\title{
A Review of Electrochromic Windows for Residential Applications
}

\author{
Sergio Sibilio ${ }^{1}$, Antonio Rosato ${ }^{1}$, Michelangelo Scorpio ${ }^{2 *}$, Giuseppina Iuliano ${ }^{1}$, \\ Giovanni Ciampi ${ }^{1}$, Giuseppe Peter Vanoli ${ }^{2}$ and Filippo de Rossi ${ }^{2}$ \\ ${ }^{1}$ Second University of Naples, Department of Architecture and Industrial Design "L. Vanvitelli", \\ via San Lorenzo, 81031, Aversa (CE), Italy \\ ${ }^{2}$ University of Sannio, Department of Engineering, Piazza Roma 21, 82100 Benevento (BN), Italy
}

Email: mscorpio@email.it

\begin{abstract}
Electrochromic windows can play an important role for energy saving as well as for controlling the visual and thermal conditions inside a room. This paper starts with a critical review and the state-of-art regarding the products today commercially available as well as the studies conducted on full scale electrochromic windows. The analysis allows to define the main parameters characterizing the electrochromic windows with particular regard to their optical, thermal and electrical characteristics, while assuming that the physical quantities, generally used to evaluate the behaviour of standard glasses, are not sufficient to evaluate the performances of the smart windows. In addition the experimental studies conducted on full scale electrochromic windows are analysed highlighting the measured physical quantities and the applied measurement methodologies considering both field and laboratory tests. Taking into account the need to accurately predict the operating characteristics and optimum design of electrochromic windows, a review of the theoretical studies available in the scientific literature as well as the developed theoretical models are presented. Finally, an experimental station for evaluating the on-site performances of different types of full scale smart windows and the layout of sensors used for the acquisition of internal and external physical quantities was described.
\end{abstract}

Keywords: Electrochromic glazing, Energy saving, Experimental measurements, Smart window, Visual comfort.

\section{INTRODUCTION}

The energy efficiency and reduction of environmental pollutants represent a common objective towards which the efforts of researchers and politicians are focused. In fact, the correct use of sun light allows to reduce energy use in buildings and improve visual comfort [1-5].

For these reasons, a great deal of projects and programs [6$8]$ have been developed to encourage the development of new devices and energy saving strategies in order to achieve the objectives set out in the European Energy Plan [6] as well as the comfort of the occupants. In this scenario, electrochromic (EC) windows can play an important role in controlling the visual and thermal conditions inside a room. Differently to conventional glazings, for which the values of visible solar transmission and solar factor are defined in the assembly stage and are not adjustable, using EC glazing allows to vary these values, by applying a small electric field (usually between 1 and $5 \mathrm{~V}$ ) to the EC device. Generally, an EC device is realized with five superimposed layers and can be considered as an electrical battery [9]. Two oxide films (cathodic and anodic) are electrically connected through an electrolyte, and then the system obtained is enclosed between two transparent electrical conductors.
The electrochromic oxides can be divided into two main types: the so-called "cathode" oxides, which change colour when ions are extracted, and the so-called "anode" oxides, which change colour when ions are inserted. At present, most of the EC windows of large surface are realised using tungsten oxide (WO3), a cathode oxide. Although a lot of studies have been conducted in order to develop and analyse new and more efficient EC materials, only a few of them take into account the behaviour of large EC windows, analysing how they affect the visual and thermal comfort in a room and their impact on the energy saving of a whole building.

The necessity to evaluate the performances of a full-scale EC glazing comes from the fact that the size of the EC layer strongly affects the characteristics and behaviour of EC glazing. In this study, the state-of-art of the marketed products and a critical review of the main parameters characterizing the EC windows behaviour from the optical, thermal and electrical point of views were presented. In the aim to identify the physical quantities acquired during field and laboratory tests as well as the used measurement methodologies, the main experimental studies conducted on full scale EC windows were analysed. In addition, a review of theoretical studies conducted on full scale EC devices was presented. 
Finally, an experimental facility for the on site characterization of different smart windows was described.

\section{COMMERCIALLY ELECTROCHROMIC WINDOWS}

AVAILABLE

In table 1, the main characteristics of available electrochromic windows, commercialized by four manufacturers (EControl-Glas GmbH \& Co.KG [10], Gesimat GmbH [11], SageGlass [12], View Dynamic Glass [13]) are shown. For the View Dynamic Glass [13] only the configurations available for both the double and triple glazing are listed. The table reports the values of the maximum size of the EC glazings marketed, the thermal transmittance $\left(\mathrm{U}_{\mathrm{g}}\right)$, the visible solar transmittance $\left(\mathrm{T}_{\mathrm{vis}}\right)$ and the solar factor $(\mathrm{SF})$. The switching time represents the time that the $\mathrm{EC}$ windows take to reach $90 \%$ of the minimum or maximum value of its visible solar transmittance. The photopic Contrast Ratio (CR) is defined as the ratio between the values of the visible solar transmittance in the most transparent (clear) to the darkest (tinted) states and represents a very important parameter for EC devices. The wider the CR value, the higher is the ability of the EC window to adapt the optical characteristics to the external condition. The analysed products show $\mathrm{CR}$ values that range from 5 to 63 . In figure 1 , the visible solar transmittances for different states of the analysed products were showed. From table 1, it can be derived that:

(1) In order to reduce the thermal transmittance of the window, the EC layer is usually coupled with double or triple glazing and low-emittance (Low-E) coated glasses.

(2) The values of the visible solar transmittance in the fully clear state start from 0.50 and 0.40 , while the values of the solar factor start from 0.32 and 0.29 , respectively, for the double and triple glazing.

(3) The values of the visible solar transmittance in the fully tinted state are not exceeding 0.10 and 0.09 , while the values of the solar factor are not exceeding 0.13 and 0.10 , respectively, for the double and triple glazing.

(4) The EC windows are supplied with direct current, whose voltage ranges from $1 \mathrm{~V}$ to $5 \mathrm{~V}$.

(5) The switching time ranges from 7 to 20 minutes.

(6) For each manufacturer, the values of the thermal transmittance influence the values of visible solar transmittance.

\section{REVIEWING THE EXPERIMENTAL STUDIES CONDUCTED ON ELECTROCHROMIC WINDOWS}

Some experimental studies on full scale and large size EC windows through field and laboratory tests were performed to evaluate their behaviour from electrical, optical and thermal points of view.

Lee et al. [15] conducted an experimental study to evaluate the performance of EC window prototypes, using a full scale office test-bed during the equinox period. The test-bed consisted of three identical side-by-side office with large-area windows south oriented, equipped with the same dimmable fluorescent lighting system. The windows of one test-bed was realised assembling fifteen $0.43 \mathrm{~m}$ x $0.85 \mathrm{~m}$ EC units, while the windows of the other two offices (used as reference) were realised with classic glasses with visible solar transmittance values equal, respectively, to 0.50 and 0.15 . An integrated EC window-lighting system controller was used to maintain inside the offices an illuminance level in the range of $510-$ 700 lx. The results show that: (i) the illuminance level range is guaranteed for $89 \%-99 \%$ of the day by daylight, (ii) the EC window allows an energy saving that can reach $59 \%$ in comparison with static windows.

Papaefthimiou et al. [16] carried out lab tests on EC window prototypes (size $0.40 \mathrm{~m} \times 0.40 \mathrm{~m}$ ) bonding (i) the EC glazing, a tungsten oxide $\left(\mathrm{WO}_{3}\right)$ based film, and (ii) an evacuated glazing. The results underlined values of the visible solar transmittance that range from 0.63 (clear) to 0.02 (tinted) as well as a good durability (over 5,000 operation cycles).

Piccolo et al [17] analysed the indoor daylighting quality reaching with an EC glazing prototype in a cooling dominated climate upon varying: (i) sky condition, (ii) orientation and (iii) switching strategy. The investigations were performed using a test-cell, $43 \mathrm{~cm}$ wide, $42 \mathrm{~cm}$ deep and $44 \mathrm{~cm}$ high, under real weather conditions during the summer season. The authors tested an EC glazing prototype, based on a tungsten oxide $\left(\mathrm{WO}_{3}\right)$ film, with a size of $0.12 \mathrm{~m} \times 0.12 \mathrm{~m}$. The main results of the research can be summarized as follows:

(1) The EC can be useful to shield the direct sun radiation, to reduce overheating and to control glare, however, in some cases, traditional shading systems could be necessary.

(2) The dynamic control strategy of the EC window allows maintaining a constant illuminance level on a workplane and to control discomfort glare.

(3) Due to its large switching time, it is not possible to follow the daylight fluctuation times under partially cloudy sky.

(4) The value of Colour Rendering Index decreases at the decreasing of the visible solar transmittance values.

In [18], the same experimental apparatus described in [17] was used to study the benefit of using EC glazing to control the discomfort glare. The acquisitions were carried out for south and west orientations; the discomfort glare was evaluated using two methods developed for daylight, the new Daylight Glare Index (DGIN) and the Glare Subjective Rating (SR). The results underlined that: (i) for south oriented windows, the EC glazing can be appropriate for guaranteeing acceptable visual comfort conditions if controlled by a dynamic strategy, (ii) for west (or east) orientation, the control of the glare effects is more difficult using only an EC window and (iii) for an adequate glare control with west (or east) oriented window, the EC windows should ensure, in the tinted state, a visible solar transmittance value lower than $7 \%$.

In their study, Lee et al. [19] analysed the interaction among EC windows and occupants. The authors took into account a west oriented conference room, in which an automatically driven EC window and a new more efficient dimmable lighting system were installed. 


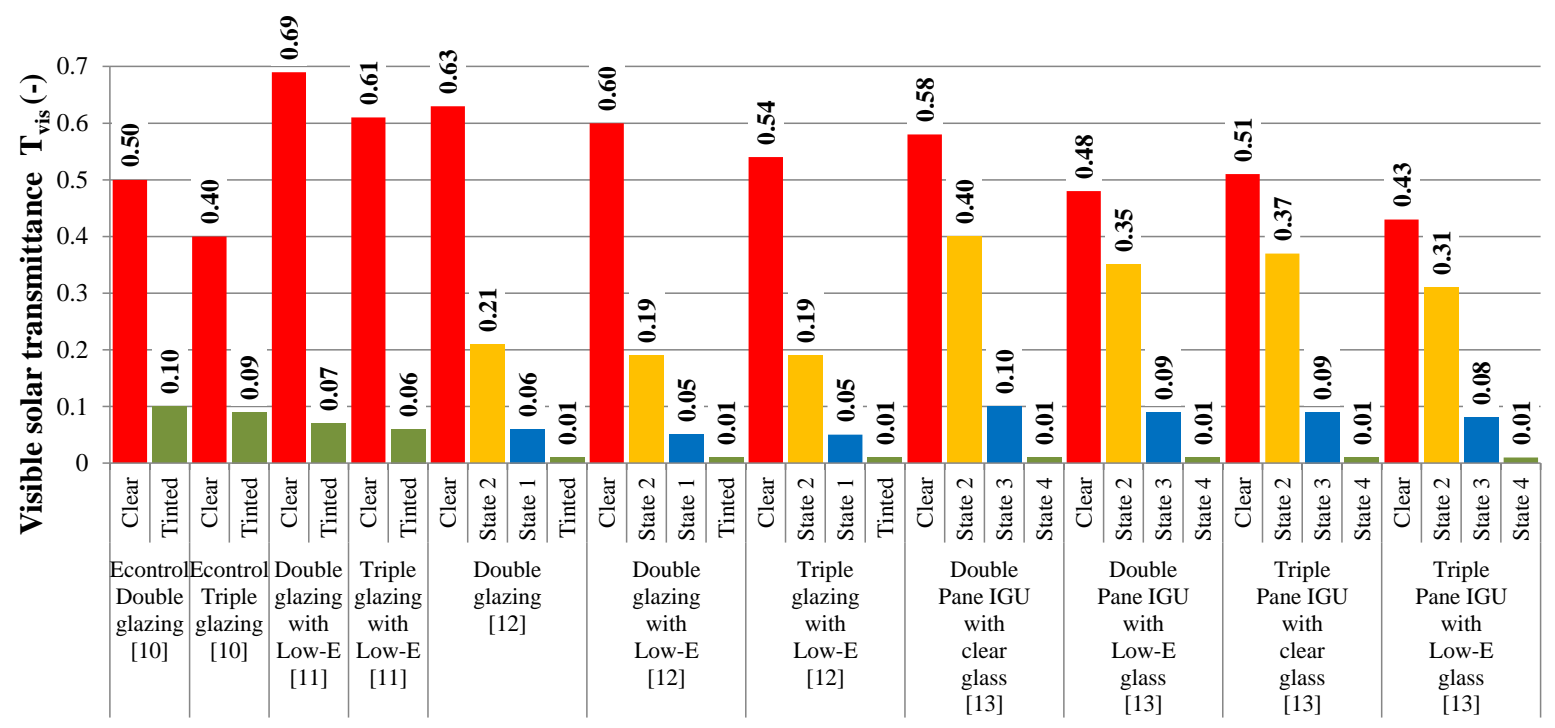

Figure 1. Values of visible solar transmittance for products and different states.

Table 1. Main characteristics of the commercially available electrochromic windows.

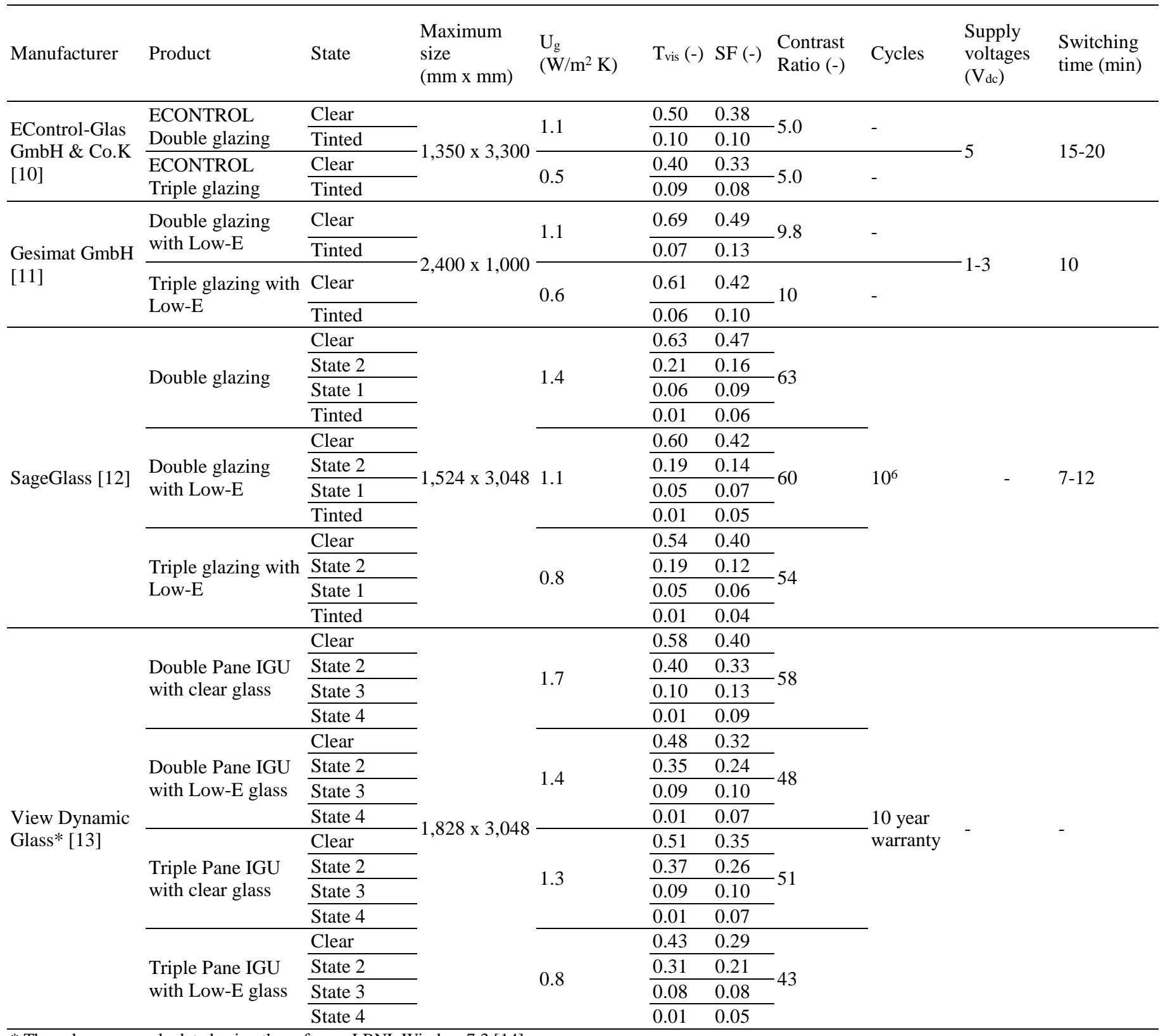

\footnotetext{
* The values were calculated using the software LBNL Window 7.3 [14].
} 
During the experimental test, the daylight illuminance levels outside and inside the room, the electrical energy for lighting, the occupancy period, the temperature on the two surfaces of the EC windows, the switching time, the time in which the windows stand in the tinted and clear state as well as the frequency with which the occupants manually adapt the EC state were controlled.

Furthermore, the room considered was modelled by the software Energy Plus, in order to estimate the annual energy use for heating, ventilation, air-conditioning and lighting as well as to determine the thermal discomfort. The main results of the research were:

(1) In $4 \%$ of the meetings the occupants operated a manual control of the EC window.

(2) The new arrangement of the room allowed for an annual energy saving that was estimated to range from $39 \%$ to $48 \%$.

(3) The peak electrical demand can be decreased from $22 \%$ to $35 \%$.

A large size organic EC window $(0.305 \mathrm{~m} \times 0.305 \mathrm{~m})$, using a new anodic monomer electropolymerized on an ITO (In2O3:Sn) coat containing a cathodic monomer, was presented and analysed in the work by Kim et al. [20]. The authors investigated the electrochemical and the optical properties through lab tests aimed at evaluating the CR value, the stability, the optical transmittance as well as the switching time. The results show:

(1) A high CR value (0.62 if evaluated at $580 \mathrm{~nm}$ and 0.57 if evaluated at $628 \mathrm{~nm}$ ).

(2) A good stability to the cyclic charge changes.

(3) A switching time of $12 \mathrm{~s}$ for colouring and of $5 \mathrm{~s}$ for bleaching.

In [21], Piccolo and Simone identified the performance indicators and the desirable values of these indicators that an EC device has to guarantee for its practical application in large area windows for buildings. The authors used the apparatus described in [17] to evaluate these performance indicators for the EC glazing prototype. The authors suggested ten significant EC performance indicators providing for each of them the desirable value:

(1) Switching voltage $(\leq 5 \mathrm{~V})$.

(2) Switching time ( $\leq 10 \mathrm{~s}$ to $5 \mathrm{~min})$.

(3) Optical memory $(2-24 \mathrm{~h})$.

(4) Visible solar transmittance coefficients (60-70\% for clear state, while for tinted state (i) 6-7 \% for energy task and (ii) $<3 \%$ for visual comfort task).

(5) Solar factor $(\geq 0.6$ for clear state and $\leq 0.2$ for tinted state).

(6) Visible solar reflectance coefficients $(\leq 0.1$ for clear state and $\geq 0.7$ for tinted state).

(7) Thermal transmittance $\left(\leq 1.2 \mathrm{~W} / \mathrm{m}^{2} \mathrm{~K}\right)$.

(8) Colour rendering $(\geq 80)$.

(9) Operating temperature $\left(-30\right.$ to $\left.90{ }^{\circ} \mathrm{C}\right)$.

(10) Lifetime (20-30 years, corresponding to 25,00050,000 operation cycles).

\section{REVIEWING THE THEORETICAL STUDIES CONDUCTED ON ELECTROCHROMIC WINDOWS}

Numerical investigations and theoretical models were performed to evaluate the benefits of using EC windows in buildings.
Gugliermetti and Bisegna [22] used the not commercial advanced simulation package Integrated ENergy Use Simulation (IENUS) to find the best control strategy of two different double glazing EC windows. The behaviour of the EC window was simulated varying the values of the optical and thermal characteristics as a function of the external solar total irradiation. The evaluations were performed in terms of primary energy required for heating, cooling and lighting with reference to an office, considering: (a) two control strategies (on/off and linear), (b) different values of the solar total radiation (set points) used to control the EC transparency, (c) three Italian cities, (d) the four main orientation of the window and (e) two different approaches to control the indoor conditions (energetic approach and visual approach). The main simulation results showed that:

(1) The energetic approach leads to a small increase in the primary energy requirement.

(2) In some cases, for the energetic approach, the static windows show performances better than the EC's.

(3) The value of the visible solar transmittance and the orientation strongly affect the optimal values of the set point used for controlling the EC states.

(4) Latitude has a small influence on the set point values.

(5) The linear control strategy allows guaranteeing a better visual comfort.

Assimakopoulos et al [23] used experimental data acquired using a test cell to validate a theoretical model of the EC window developed in the TRNSYS dynamic simulation software. During the experimental tests, the internal and external temperatures of the test cell surfaces, ambient air temperature, wind speed, internal air temperature, diffuse irradiance and global irradiance on horizontal and south vertical plane, internal illuminance, external global and diffuse horizontal illuminance as well as the temperature of the internal and external glazing surfaces were acquired. The theoretical windows model was validated by comparing the measured values of the internal air temperature with those predicted by the simulation. The validated model was used to simulate different glazings type and two control strategies for the EC's. The main results of the research were that the best strategy is to control the EC window characteristics as a function of the external conditions

In [24], the authors, through the same simulation software of [22], evaluated the best control strategies for dimming artificial lighting and the EC windows that allow to maintain a set illuminance value inside an office, minimizing the energy consumption. For both the artificial lighting and EC windows two control strategies were considered: (i) an on/off control strategy and (ii) a linear control strategy. The simulations were performed considering: 1) different types of EC windows, 2) typical windows with motorized shading devices with different values of the visible solar transmittance, 3) three different cities and 4) two window orientations (south and north). The simulation results underline that:

(1) For Rome, a clear double glazed system works better than the EC windows, whatever the control strategy is.

(2) The EC window ability to reduce energy use for lighting and guarantee environmental comfort decreases upon increasing the latitude.

(3) For north orientation, the on/off and the linear control strategies of the EC window confirm the same results. 
In his work, Piccolo [25] started with the experimental characterization of an EC prototype $(0.12 \mathrm{~m} \times 0.12 \mathrm{~m})$ based on tungsten oxide $\left(\mathrm{WO}_{3}\right)$. Through a test cell, the ability of the EC prototype to control the light transmitted, the solar factor and the internal temperature under real weather conditions during the summer season were analysed. The tests were performed for south and west orientations as well as considering two control strategies of the EC prototype (static and dynamic). Using the experimental data, a theoretical model capable of describing the transient thermal behaviour of the test cell was developed and validated. The model consisted of a list of one-dimension transient energy balance equations that used the experimental data acquired on the external air temperature, the global vertical irradiance and the vertical irradiance measured behind the internal surface of the EC prototype as inputs. Comparing the experimental values of the internal air temperature with those simulated, the different percentage was within $3 \%$. After validation, the model was used to simulate the heating load required for the test cell, considering different types of glazings. The results showed that, when the EC window was controlled according to a dynamic strategy, it was possible to achieve a reduction of about $31 \%$ in thermal load and that this reduction was similar to that obtainable with a double-glazed low-emittance window.

Aldawoud [26] modelled an office building in the simulation software DesignBuilder in order to evaluate the efficacy of EC windows, in comparison with conventional exterior shading systems to control the overheating due to solar radiation in hot and dry climates. The results highlighted that: (i) the EC windows are the best solution among those analysed and (ii) in comparison with the not shaded double-glazed windows, the EC windows allow a monthly reduction in solar heat gain from $53 \%$ to $59 \%$.

Fernandes et al. [27] conducted a simulation study in order to evaluate the lighting energy saving achievable using an EC window. The study simulated a south facing private office with two independent EC windows. Through the simulation software Radiance, the interior luminance and illuminance values were obtained for the whole year with a time step of one hour. On the basis of the simulation results, an optimization algorithm was used to determine the configuration of the EC window and the contribution of the artificial lighting with the aim of guaranteeing an illuminance target on the work-plane. The research results highlighted a remarkable potentiality of the EC windows used on the south façade in energy saving; if compared with a clear glass, an EC window allowed an energy saving of about $48 \%$.

Tavares et al. [28] modelled the EC windows behaviour adapting a module called "Black Box Model" designed for the ESP-r simulation software. The model was used to evaluate the way EC windows can modify the energy consumption for the heating and cooling of a building located in Coimbra (Portugal). The simulations were performed considering: 1) different types of glazings, 2) different control strategies for the EC window and 3) different orientations. The simulation results revealed that: (i) the EC windows were proved to be useful only for the cooling season and (ii) in terms of annual energy need, the greatest energy saving was found for the west orientation, while no benefits were observed for the north orientation of the EC windows.

\section{DESCRIPTION OF THE EXPERIMENTAL STATION AND MEASUREMENT SET-UP}

Starting from the need for additional experimental and theoretical studies on full scale EC windows as well as to assess on-site the performances of all "smart" solution for windows, an experimental station was designed and set-up at the Department of Engineering of the University of Sannio. The station consists of a main supporting steel structure, with an external size of $6.00 \mathrm{~m} \times 6.00 \mathrm{~m}$ and height of $5.50 \mathrm{~m}$ that support three removable and one not movable wall. The fixing systems of the removable walls and window were realised with the purpose of allowing their easy substitution, and then the characterization of different types of walls and windows. The cooling and heating control systems as well as the experimental data acquisition systems were installed on the not movable wall. Figure 2 shows the external view of wall where can be installed the window to test. The test facility structure was placed on a turntable with the purpose of adjusting the orientation of the experimental station.

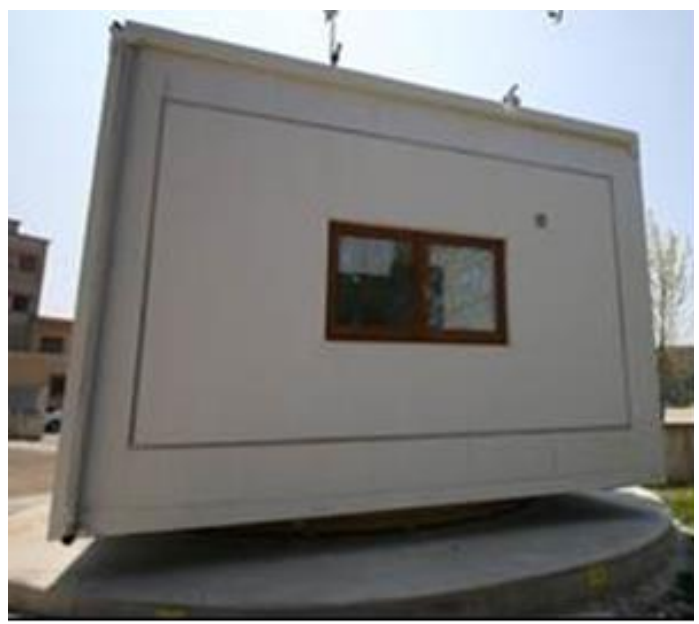

Figure 2. External view of the experimental station and window

The standard window considered for the measurement system set up, has a wood frame with a total size of $2.000 \mathrm{~m} \mathrm{x}$ $1.200 \mathrm{~m}$, ratio between glass area and total window area equal to 0.59 and a distance (from the middle point of the window) to the ground of about $2.750 \mathrm{~m}$. Two conventional double low-emitting glazing panes filled with Argon (each with size $0.785 \mathrm{~m}$ x $0.900 \mathrm{~m}$ ), produced by Saint-Gobain [29] were installed. According to the technical data declared by the manufacturer, the glass was characterized by a visible solar transmittance $\left(\mathrm{T}_{\mathrm{vis}}\right)$ equal to $80 \%$, a thermal transmittance $\left(\mathrm{U}_{\mathrm{g}}\right)$ equal to $1.1 \mathrm{~W} / \mathrm{m} 2 \mathrm{~K}$ and a solar factor (SF) equal to 0.63 .

The surfaces of the room and furniture were experimentally characterized recording the reflectance values with the spectrophotometer Konica Minolta CM - 2600d [30] (size of integrating sphere: $\varnothing 52 \mathrm{~mm}$, wavelength range: from $360 \mathrm{~nm}$ to $740 \mathrm{~nm}$ and spectral reflectance: standard deviation within $0.1 \%)$. The reflectance measurements were performed on three measurement points for each room surface and their values were evaluated considering the standard illuminant D65 and the Specular Component Included (SCI). The reflectance value on each measuring point was obtained as the mean value of three measurements, while the reflectance 
values assigned to the surface were calculated as the average value of the data recorded on the three measurement points.

In the table 2 , the experimental reflectance values of the main internal surfaces of the facility were listed.

Table 2. Experimental reflectance values of internal surfaces

\begin{tabular}{ll}
\hline Surface & Values of D65 reflectance SCI $(\%)$ \\
\hline Floor & 55.1 \\
\hline Walls & 86.8 \\
\hline Ceiling & 79.2 \\
\hline Window frame & 17.2 \\
\hline Door & 54.6 \\
\hline
\end{tabular}

In order to evaluate the real availability of daylight, the external values of the horizontal global and diffuse illuminance were acquired. Both horizontal illuminance values were acquired on the roof of the experimental station using two illuminance-meters LP PHOT 03 (manufactured by Delta OHM [31], with cosine correction, measuring range from $01 \mathrm{x}$ to $150,000 \mathrm{~lx}$, relative spectral response (f1') $<6 \%$ and accuracy $<4 \%$ ). The figure 3 shows the arrangement of the sensor for the measurement of the external horizontal diffuse illuminance values.

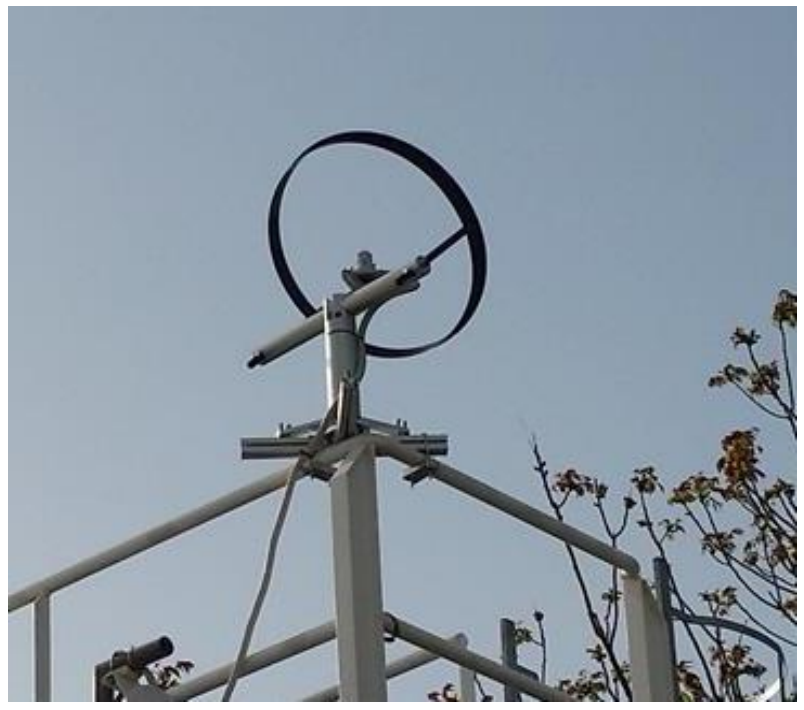

Figure 3. Sensor for measuring the horizontal diffuse illuminances.

For the measurement of the horizontal diffuse illuminance, the illuminance-meter was equipped with a black painted shadow-ring with diameter of $0.574 \mathrm{~m}$ and a thickness equal to $0.052 \mathrm{~m}$ in order to shade the direct radiation from the sun.

The shadow-ring is a static system able to block the direct sun radiation, guaranteeing a permanent shadow on the sensor. As consequence, the shadow-ring blocks a significant portion of the sky vault. For this reason, the experimental data measured by the above-mentioned system have to be corrected with a geometrical correction factor in order to take into account the portion of sky obscured by the shadow ring. Furthermore, a further correction factor must be applied to take into account the anisotropic luminance sky distribution of clear sky conditions. In the aim of taking into account both correction factors, the experimental horizontal diffuse illuminance values were corrected following the methodology proposed by Battles et al. [32]. Thanks to the sky luminous efficacy function, that allows to convert irradiance values to illuminance values and vice versa, this methodology was used for correcting the horizontal illuminance values measured with the shading-ring, even if the sensor was developed for irradiance measurements.

The measurements of internal daylight illuminance distribution were performed with the window south oriented; both the external and internal photometric quantities were acquired with a time step of 10 minutes. The internal daylight distribution was evaluated in nine measurement points arranged inside the room, through nine illuminance-meters Konica Minolta T-10 [30] with cosine correction, measuring range from $0.01 \mathrm{~lx}$ to $300,000 \mathrm{~lx}$ and accuracy of $\pm 2 \%$. By means of suitable support structures, the illuminance-meters were placed at $0.85 \mathrm{~m}$ from the floor level in horizontal position. Figure 4 shows the layout of the experimental station and the position of the illuminance sensors (indicated with a number from $\mathrm{H} 1$ to $\mathrm{H} 9$ ) used to evaluate the internal daylight illuminanace distribution. The measurement points were identified considering a grid subdivision of the total area in a $3 \times 3$ array with single cell $1.410 \mathrm{~m} \times 1.540 \mathrm{~m}$ each; the sensors were placed at the centre of each small area.

With the purpose to investigate the luminance distribution and the occurrence of glare, internal luminance maps can be acquired using a videoluminance-meter LMK 98-3 Colour manufactured by the company TechnoTeam [33]. In the aim of reproducing a hypothetical office work station, a desk was arranged inside the experimental station on the left side of the window.

A $0.38 \mathrm{~m}$ notebook was placed on the desk and the videoluminance-meter was positioned at the eye level of a person considered as seated at the desk, facing and looking at the screen of the notebook. It was equipped with a fisheye lens TT4.5, focal length of $4.5 \mathrm{~mm}$, relative spectral response (f1') equal to $2.6 \%$ and accuracy equal to $\pm 3.7 \%$.

In the figure 4 , the relative position of the notebook (PC), the videoluminance-meter (VL) and the window were depicted.

The figure 5 shows the internal view of the test room. In this figure the position of both the window and the illuminance sensors as well as the supporting structures used for the correct positioning of the illuminance-meters can be easily identified.

\section{CONCLUSIONS}

EC devices can offer several benefits in comparison with conventional static glazings. Experimental and numerical studies underlined the benefit of EC windows and suggested the use of automatically driven EC devices for energy saving, visual comfort and control of direct solar radiation. Nevertheless if on the one hand the use of EC devices can allow an energy saving that ranges from $39 \%$ to $59 \%$, on the other hand the real benefits are strongly influenced by orientation, control strategy (static or dynamic), climatic condition and location in which EC windows will be installed. Regarding the orientation, negligible advantages were noticed for EC devices north faced, whilst for increased latitude, the benefits in energy saving and visual comfort decrease in comparison with static standard glazings; last but not least, the long switching time (7-20 minutes) prevents the EC windows to follow the real weather conditions.

Generally, further experimental and numerical studies are needed in order to understand the physical behaviour of the 
large area EC windows and to define their real benefit for different operating conditions.

The experimental station set up at the Department of Engineering of the University of Sannio for the on site characterization of different smart windows was described. The facility is equipped with many measurement sensors to acquire internal and external physical parameters.

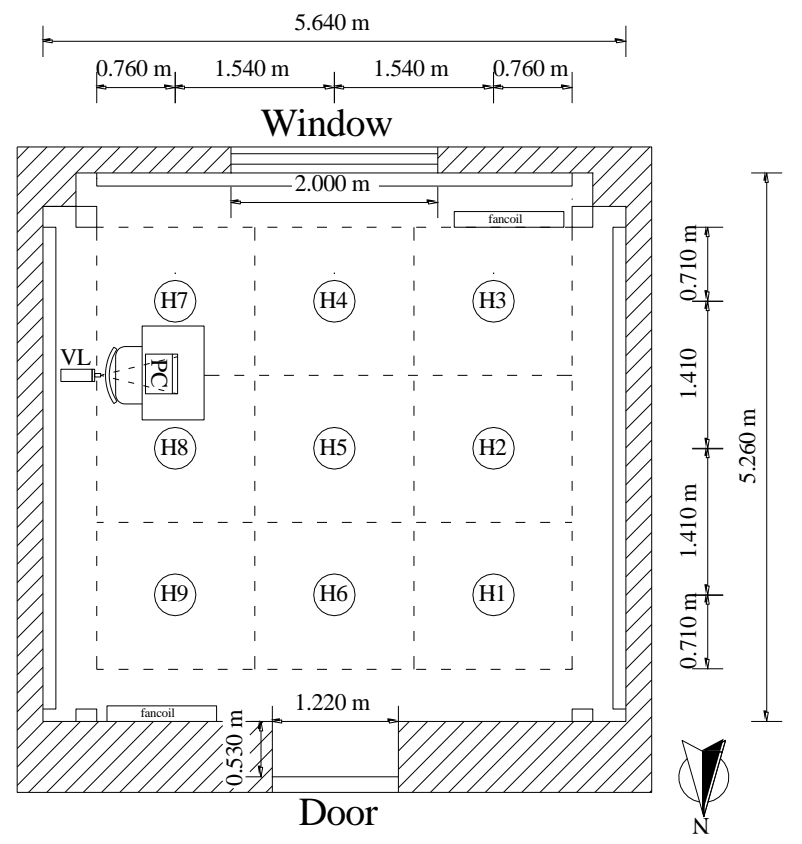

Figure 4. Layout of the experimental station as well as the position of illuminance-meters (from $\mathrm{H} 1$ to $\mathrm{H} 9$ ) and videoluminance-meter (VL)

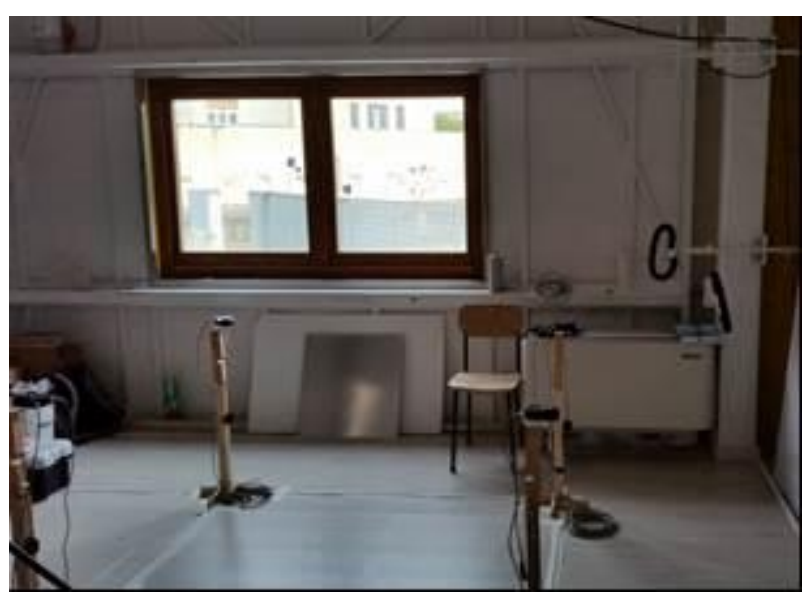

Figure 5. Internal view of the test room with positioning of the illuminance sensors

\section{REFERENCES}

[1] A. Rosato, M. Scorpio and S. Sibilio., "Use of a scale model under artificial sky for daylighting design," Heritage Architecture Landesign focus on Conservation Regeneration Innovation Le vie dei Mercanti XI Forum Internazionale di Studi, Aversa. Capri, pp. 1245-1252, 2013.

[2] G. Ciampi, A. Rosato, M. Scorpio and S. Sibilio., "Daylighting measurements and evaluation of the energy saving in an historical building," Heritage and
Technology focus on Mind Knowledge Experience Le Vie dei Mercanti XIII Forum Internazionale di Studi. Aversa. Capri, 2015, pp. 1977-1986.

[3] G. Ciampi, A. Rosato, M. Scorpio and S. Sibilio., "Retrofitting solutions for energy saving in a historical building lighting system," Energy Procedia. vol. 78, pp. 2669-2674, 2015. DOI: 10.1016/j.egypro.2015.11.343.

[4] G. Ciampi, A. Rosato, M. Scorpio, S. Sibilio and Sergio., "Daylighting Contribution for energy saving in a historical building," Energy Procedia. vol. 78, pp. 1257-1262, 2015

DOI:

10.1016/j.egypro.2015.11.270.

[5] S. Sibilio, A. Rosato and M. Scorpio., "Daylighting design in a low energy building," Lux Europa. Krakow, pp. 251-256, 2013.

[6] http://ec.europa.eu/energy/en/topics/energy-efficiency (accessed on 26/04/2016).

[7] http://www.enlight-project.eu/en/home/ (accessed on 26/04/2016).

[8] http://iet.jrc.ec.europa.eu/energyefficiency/greenlight (accessed on 26/04/2016).

[9] C. G. Granqvist., "Electrochromics for smart windows: Oxide-based thin films and devices," Thin Solid Films vol. 564, pp. 1-38, 2014. DOI: 10.1016/j.tsf.2014.02.002.

[10] http://www.econtrol-glas.de/en/home/ (accessed on 26/04/2016).

[11] http://www.gesimat.de/elektrochrom.html (accessed on 26/04/2016).

[12] http://sageglass.com/ (accessed on 26/04/2016).

[13] http://viewglass.com/ (accessed on 26/04/2016).

[14] https://windows.lbl.gov/software/window/7/index_7_3 _4.html (accessed on 26/04/2016).

[15] E. S. Lee, D. L. Dibartolomeo and S. E. Selkowitz., "Daylighting control performance of a thin-film ceramic electrochromic window: Field study results," Energy Build. vol. 38, pp. 30-44, 2006. DOI: 10.1016/j.enbuild.2005.02.009.

[16] S. Papaefthimiou, G. Leftheriotis, P. Yianoulis, T. J. Hyde, P. C. Eames, Y. Fang, P. Y. Pennarun and P. Jannasch., "Development of electrochromic evacuated advanced glazing," Energy Build. vol. 38, pp. 14551467, 2006. DOI: 10.1016/j.enbuild.2006.03.029.

[17] A. Piccolo, A. Pennisi and F. Simone., "Daylighting performance of an electrochromic window in a small scale test-cell," Sol. Energy. vol. 83, pp. 832-844, 2009. DOI: 10.1016/j.solener.2008.11.013.

[18] A. Piccolo and F. Simone., "Effect of switchable glazing on discomfort glare from windows," Build. Environ. vol. 44, pp. 1171-1180, 2009. DOI: 10.1016/j.buildenv.2008.08.013.

[19] E. S. Lee, E. S. Claybaugh and M. LaFrance., "End user impacts of automated electrochromic windows in a pilot retrofit application," Energy Build. vol. 47, pp. 267-284, 2012. DOI: 10.1016/j.enbuild.2011.12.003.

[20] S. Kim, X. Kong and M. Taya., "Electrochromic windows based on anodic electrochromic polymesitylenes containing 9H-carbazole-9-ethanol moieties," Sol. Energy Mater. Sol. Cells., vol. 117, pp. 183-188, 2013. DOI: 10.1016/j.solmat.2013.04.030.

[21] A. Piccolo and F. Simone., "Performance requirements for electrochromic smart window," J. Build. Eng. vol. 3, pp. 94-103, 2015. DOI: 10.1016/j.jobe.2015.07.002. 
[22] F. Gugliermetti and F. Bisegna., "Visual and energy management of electrochromic windows in Mediterranean climate," Build. Environ. vol. 38, pp. 479-492, 2003. DOI: 10.1016/S0360-1323(02)00124$\underline{5 .}$

[23] M. N. Assimakopoulos, A. Tsangrassoulis, G. Guarracino and M. Santamouris., "Integrated energetic approach for a controlable electrochromic device," Energy Build. vol. 36, pp. 415-422, 2004. DOI: 10.1016/j.enbuild.2004.01.040.

[24] F. Gugliermetti and F. Bisegna., "A model study of light contrai systems operating with Electrochromic Windows," Light. Res. Technol. vol. 37, no. 1 pp. 3 20, 2005. DOI: 10.1191/1365782805li123oa.

[25] A. Piccolo, "Thermal performance of an electrochromic smart window tested in an environmental test cell," Energy Build, vol. 42, pp. 1409-1417, 2010.

DOI: 10.1016/j.enbuild.2010.03.010.

[26] A. Aldawoud, "Conventional fixed shading devices in comparison to an electrochromic glazing system in hot, dry climate," Energy Build. vol. 59, pp. 104-110, 2013. DOI: $10.1016 /$ j.enbuild.2012.12.031.
[27] L. L. Fernandes, E. S. Lee and G. Ward, "Lighting energy savings potential of split-pane electrochromic windows controlled for daylighting with visual comfort," Energy and Buildings, vol. 61, pp. 8-20, 2013. DOI: 10.1016/j.enbuild.2012.10.057.

[28] P. F. Tavares, A. R. Gaspar, A. G. Martins and F. Frontini., "Evaluation of electrochromic windows impact in the energy performance of buildings in Mediterranean climates," Energy Policy, vol. 67, pp. 68-81, 2014. DOI: 10.1016/j.enpol.2013.07.038.

[29] http://it.saint-gobain-glass.com/product/1897/sggplanitherm-inox (accessed on 26/04/2016).

[30] http://www.konicaminolta.eu/it/strumenti-dimisura/home.html (accessed on 26/04/2016).

[31] http://www.deltaohm.com/ver2012/ (accessed on 26/04/2016).

[32] F. Battles, L. Alados-Arbodelas and F. Olmo, "On shadow band correction methods for diffuse irradiance measurements," Solar Energy, vol. 54, pp. 105-114, 1995. DOI: 10.1016/0038-092X(94)00115-T.

[33] http://www.technoteam.de/index_eng.html (accessed on $26 / 04 / 2016$ ). 